\title{
Too much is bad: increasing numbers of livestock and conspecifics reduce body mass in an avian scavenger
}

\author{
José A. Donázar iD 1,4 Jomar M. Barbosa, ${ }^{1,2}$ Marina García-Alfonso, ${ }^{1}$ ThijsvanOverveld, ${ }^{1}$ Laura \\ Gangoso id , ${ }^{1,3}$ and Manuelde laRiva ${ }^{1}$ \\ ${ }^{1}$ Department of Conservation Biology, Estación Biológica de Doñana (CSIC), Avenida Americo Vespucio 26, 41092 Sevilla, Spain \\ ${ }^{2}$ Department of Applied Biology, University Miguel Hernández, Elche, Spain \\ ${ }^{3}$ Institute for Biodiversity and Ecosystem Dynamics, University of Amsterdam, Science Park 904, 1098 XH Amsterdam, The \\ Netherlands
}

Citation: Donázar, J. A., J. M. Barbosa, M. García-Alfonso, T. van Overveld, L. Gangoso, and M. de la Riva. 2020. Too much is bad: increasing numbers of livestock and conspecifics reduce body mass in an avian scavenger. Ecological Applications 00(00):e02125. 10.1002/eap.2125

Abstract. Individual traits such as body mass can serve as early warning signals of changes in the fitness prospects of animal populations facing environmental impacts. Here, taking advantage of a 19-yr monitoring, we assessed how individual, population, and environmental factors modulate long-term changes in the body mass of Canarian Egyptian vultures. Individual vulture body mass increased when primary productivity was highly variable, but decreased in years with a high abundance of livestock. We hypothesized that carcasses of wild animals, a natural food resource that can be essential for avian scavengers, could be more abundant in periods of weather instability but depleted when high livestock numbers lead to overgrazing. In addition, increasing vulture population numbers also negatively affect body mass suggesting density-dependent competition for food. Interestingly, the relative strength of individual, population and resource availability factors on body mass changed with age and territorial status, a pattern presumably shaped by differences in competitive abilities and/or age-dependent environmental knowledge and foraging skills. Our study supports that individual plastic traits may be extremely reliable tools to better understand the response of secondary consumers to current and future natural and human-induced environmental changes.

Key words: body mass; density dependence; grazing; individual traits; NDVI; vulture.

\section{INTRODUCTION}

The complex relationships between climate, vegetation, and the dynamics of animal populations have generated great interest in ecological research (Simard et al. 2010), with a growing focus on individual indicators as early warning signals of changes in demographic parameters of animal populations facing environmental impacts (Clements and Ozgul 2016). Among these indicators, body mass has been widely used as an indicator of animal fitness, mainly of primary consumers (Pettorelli et al. 2007, Couturier et al. 2009, Rioux Paquette et al. 2014, Duncan et al. 2015). However, there is comparatively much less information regarding secondary consumers, although primary productivity is known to influence population dynamics of different groups, from arthropods to large vertebrates (Buschke et al. 2011, Deichmann et al. 2012, Pierce et al. 2012). In addition, research on body condition (i.e., body mass) of secondary consumers and its relationship to ecosystem-

Manuscript received 27 September 2019; revised 15 January 2020; accepted 29 January 2020. Corresponding Editor: Dianne Brunton.

${ }^{4}$ E-mail: donazar@ebd.csic.es level processes can improve our understanding of the effects of human-induced environmental change on food webs (Coulson et al. 2011).

Anthropogenic modifications of primary productivity at ecosystem-level, notably through agriculture and livestock farming, can aggravate the consequences of climatic impacts on wild animals (Darkoh 2003, Beschta et al. 2013), also disrupting species interactions across trophic levels (Rosenblatt 2018). The negative consequences of livestock expansion (Ellis 2011) are exacerbated in oceanic islands, where the introduction of domestic ungulates has also led to high extinction rates of native fauna and flora (Coblentz 1978, Chapuis et al. 1994). However, in some island systems, introduced ungulates have been deeply rooted in their ecosystems for millennia (Zeder 2008), even becoming keystone species in the food webs when native herbivores became extinct (Hunter 1992, Gangoso et al. 2006).

Farming practices have favored the establishment of a win-win relationship between humans and avian scavengers that feed on livestock carcasses (O'Neal 2015), also promoting the occurrence of traditionally abundant vulture populations in different archipelagoes, from Macaronesia and the Mediterranean (Donázar et al. 2005) to the Indian Ocean (Gangoso et al. 2013). In 
these closed ecological scenarios, cascading climate-driven effects across different trophic levels and intraspecific competition for resources (Carrete et al. 2006, Fernández-Bellon et al. 2016, Heuck et al. 2017) may determine fluctuations of vulture populations and individual body condition. However, we still do not know the relative importance of climate-driven biotic interactions and human-induced modifications of the ecosystems in relation to individual- and population-level factors in these processes.

Here, we test how changes in primary productivity, trophic resources and density-dependent factors may modulate changes in individual body mass of an insular scavenger, taking advantage of a unique long-term monitoring (19 yr) program of the endemic Canarian Egyptian vulture (Neophron percnopterus majorensis). We predict (Table 1) that vultures will gain body mass in periods of high and/or very variable primary productivity, because this would in turn increase the availability of natural food resources (carcasses of wild primary consumers). We also expect that vulture body mass will increase in periods of high availability of livestock carcasses. In contrast, vulture body mass will decrease in parallel with the overall population increase due to density-dependent factors. Because bird sex and age determine foraging strategies in this population, with females and immature individuals relying more on predictable resources (García-Heras et al. 2013, van Overveld et al. 2018), we predict that body mass of females and immature vultures will be more affected by livestock abundance and intraspecific competition than by changes in landscape-scale primary productivity. Disentangling the complex relationships among ecosystem-level factors, population structure, and individual characteristics that determine animal body condition will help define management strategies for this and other ecologically similar endangered populations.

\section{Methods}

\section{Field procedures}

The population of Canarian Egyptian vultures was intensively monitored in Fuerteventura Island from 1999 to 2017. Complete censuses were carried out annually by means of intensive surveys of all those areas susceptible of holding territorial vultures. In addition, all fledglings were ringed and several adult and immature birds were captured and ringed each year. Fledglings were captured at nests whereas immature and adult birds were captured in baited places using cannon nets. Thus, in 2017, of 311 individuals (148 breeders and 163 nonbreeders) $89.7 \%$ were banded (121 and 158 birds respectively). During the whole study period, a total of 394 individuals were captured, of which 123 were recaptured. Capture effort was intensified in $2015(n=77)$ aimed at tagging individuals with GPS trackers. The highest frequency of captures took place in May-June $(n=225)$ and September-October $(n=107)$, while no captures were made in July, August, or December (Appendix S1; Fig. S2). Accordingly, these captures were distributed into two categories: breeding and non-breeding Season (February-June and September-January, respectively).

All birds were weighed using a Pesola scale $( \pm 5 \mathrm{~g})$. Only a very small number of birds used to have full crops during handling (two of 116 individuals, $1.7 \%$, examined between 2013 and 2015). In fact, Egyptian vultures usually vomit after being captured, as other scavengers do when facing predators (O'Neal 2015), so this circumstance would not affect our results. Wing chord length (Wing) was measured using a $100-\mathrm{cm}$ rule to the nearest $\mathrm{mm}$. Wing chord length is a reliable and widely used proxy for body size (Ashton 2002, Van Buskirk et al. 2010, Rioux Paquette et al. 2014). The age of the individuals captured was known either because they were ringed as fledglings or because at the time of first capture they were immature with a distinctive transition plumage. Following (Forsman 2007), we distinguished five plumages between fledgling and adult age. Adult birds were those having acquired the fifth plumage ( $\geq 6 \mathrm{yr}$ old). We discarded recently fledged young whose condition mainly depends on their recent development history. Data on the annual breeding vulture population size (Population) were considered as an estimator of intraspecific competence for food resources (van Overveld et al. 2018). See Appendix S1 for details on the study area and species.

\section{Primary productivity and food resource availability}

We used the Normalized Difference Vegetation Index (NDVI) derived from satellite sensors as a proxy for vegetation productivity and biomass (Pettorelli et al. 2005, De La Maza et al. 2009) and, consequently, for availability of wild primary consumers to vultures. We used a gridded daily NDVI data set from the NOAA Climate Data Record (CDR) of Advanced Very High Resolution Radiometer (AVHRR; Vermote et al. 2014). The NDVI products are computed from an atmospherically corrected bidirectional surface reflectance that has been masked for water, clouds, heavy aerosols, and cloud shadows. Per-pixel quality assessment metadata were used to check the product performance to measure the NDVI throughout the years. We first calculated mean monthly values of NDVI for the study period (Appendix S2). From this, we estimated five different variables: primary productivity in each year (annual NDVI), in the month of the vulture capture (NDVImonth), and monthly average NDVI of the two and six months before the capture (NDVI2month and NDVI6month, respectively), as well as the coefficient of variation of the mean values in these periods (CVNDVI2month and CVNDVI6month). We used these different NDVI variables to evaluate the relative importance of NDVI average, seasonality and potential time-lag effects (Sloat et al. 2018). 


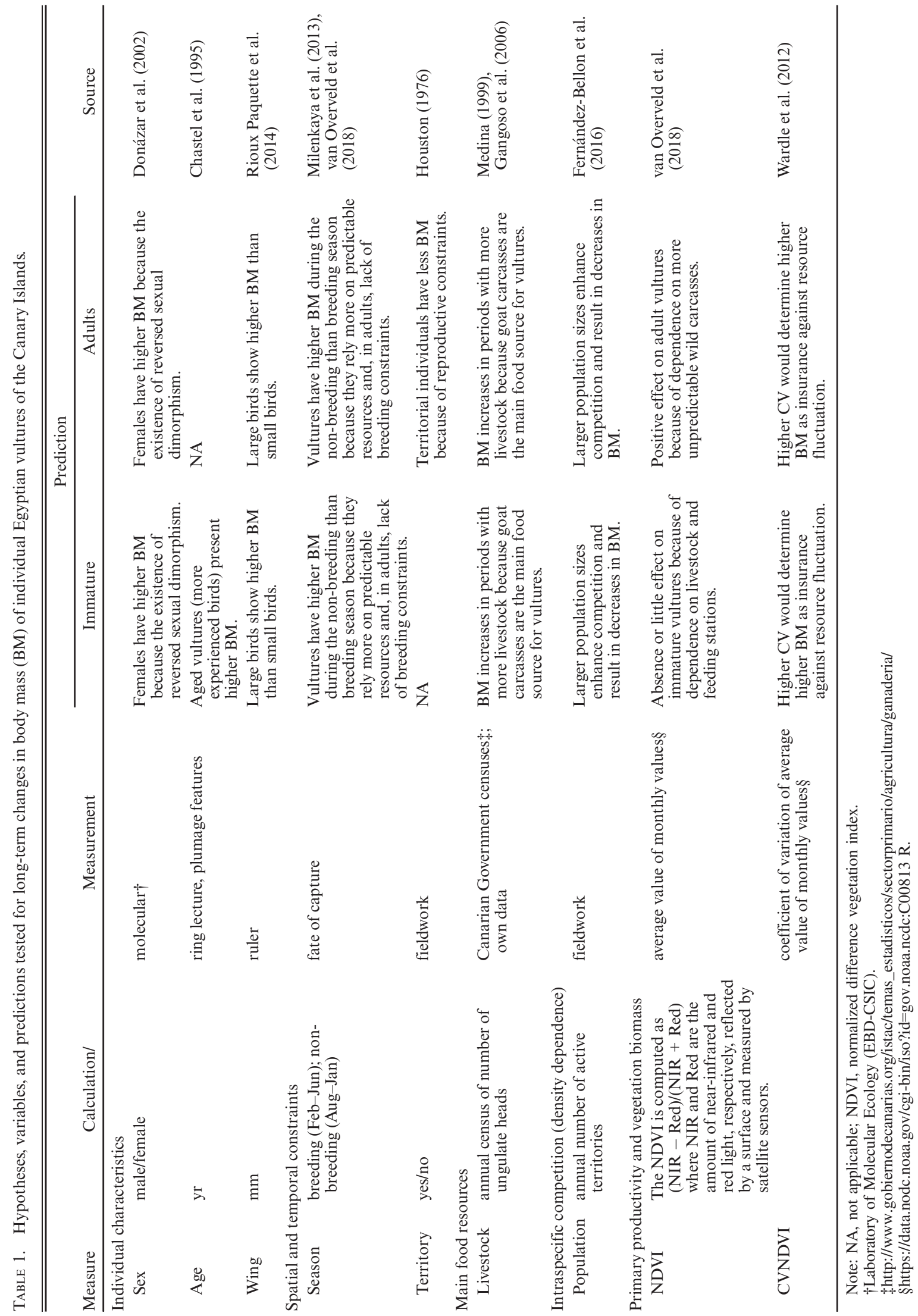


Availability of livestock carcasses (Livestock) was estimated from livestock numbers assuming that an increase in domestic ungulates leads to an increase in the number of carcasses available for vultures (Fillios et al. 2010, Margalida and Colomer 2012). We obtained the annual number of goat and sheep held in farms on Fuerteventura from governmental databases up to 2014 and author data from 2015 to 2017 (see Data Availability and databases available online). ${ }^{5}$ Despite European sanitary regulations implemented in 2004-2005 (Donázar et al. 2009, Margalida and Colomer 2012, Margalida et al. 2014), carcass removal from farms has been only partially implemented in the study area: during 2015 we performed 94 interviews to farmers; 57 of them (61\%) admitted that they left livestock carcasses near their exploitations. Because overgrazing may be an important factor affecting primary productivity (Pandey and Singh 1992, Gangoso et al. 2006), we analyzed how both livestock numbers and precipitation influenced annual NDVI. As expected (Sloat et al. 2018, Liang and Gornish 2019), primary productivity was positively affected by rainfall, while livestock numbers exerted a negative effect (see Appendix S2 for details).

\section{Data analyses}

We assessed variation in the Egyptian vultures' body mass (g) as a function of individual, population, and environmental characteristics (see data in Appendix S4). We split the database according to two broad age categories: immature (first-fourth plumage: up to fifth calendar year) and adult birds (fifth plumage: $\geq$ sixth calendar year). We performed separate linear mixed models (LMM) with identity link function for immatures and adults, where individual Body mass was included as the response variable. Explanatory variables (Table 1) described the period of capture (Season) and individual characteristics (Sex, Age, and Wing). Age was fitted only for immature birds. For adults, a previous analysis confronting Age and Body mass using only individuals with known age showed no correlation $\left(r_{\mathrm{S}}=0.149, P=0.184, n=81\right)$. Consequently, in the final models for adult birds we included all the individuals over six years old even if their exact age was unknown. Wing accounts for potential variability associated with body size (Rioux Paquette et al. 2014). As these authors explain, although the use of body condition indices (e.g., regression residuals) is widespread, it has been suggested that body mass alone often outperforms condition indices as a measure of fat content in bird species. Consequently, they propose to use body mass as a proxy for condition, while including a size covariate (wing length in our case) to effectively correcting mass for size (see Rioux Paquette et al. 2014). The variable Territory, which describes whether the vultures were territorial breeders in the year of capture, was also included in

\footnotetext{
${ }^{5}$ http://www.gobiernodecanarias.org/istac/temas_estadisticos/ sectorprimario/agricultura/ganaderia/
}

models for adult birds. In addition, we tested the effects of availability of food resources (Livestock and those variables related to NDVI) and density dependence (Population). Finally, because the study species presents reversed sexual dimorphism, with females being slightly larger (6.1\%) than males (Appendix S4) and both sexes differ in foraging strategies (van Overveld et al. 2018), we included the two-way interactions between $S e x$ and all other variables (Table 1). In all models, the variable Individual was included as a random term to account for repeated measurements of the same bird. All continuous variables were scaled prior to analyses. Models were fitted with all possible combinations of explanatory variables, except for pairs of variables with a Spearman's correlation coefficient higher than $|0.5|$ to avoid collinearity (Grahman 2003).

We used Akaike Information Criterion corrected for small sample sizes ( AIC $_{\mathrm{c}}$; Sugiura 1978) for model selection. We considered as statistically equivalent those models with $\Delta \mathrm{AIC}_{\mathrm{c}}<2.0$ and used model averaging to deal with model selection uncertainty (Burnham and Anderson 2002). We discarded models including uninformative parameters, namely those whose $85 \%$ confidence intervals overlapped with 0 (Arnold 2010). All analyses were carried out in R statistical software ( $R$ Core Team 2017) using the stats package for LM and confidence intervals, Ime4 (Bates et al. 2014) for the LMM analysis, AICcmodavg (Mazerolle 2019) for model ranking, and MuMIn (Barton 2017) for model averaging.

\section{RESUlTS}

Individual variation in the Egyptian vultures' body mass depended on Sex, Wing, Age, and Season (Fig. 1). Strong variations in body mass across years during the study period were also apparent (Fig. 2). Only one model was retained for immature birds, whereas for adults we obtained five candidate models (Appendix S3). Final models (averaged models for adults) showed some common patterns for both age classes (Table 2, Fig. 3). Thus, Body mass was higher for females and for individuals with larger body size (Wing). However, the interaction between these two variables indicated that the effect of Wing on Body mass was strong for females and almost non-existent for males. We also found a negative effect of Livestock numbers and a positive effect of the CVNDVI6month on the body mass of both age groups (Fig. 3). With regard to other variables, however, immatures and adults showed divergent patterns. Immatures gained mass with Age and during the non-breeding Season, but seasonal effects were not apparent in adults. In addition, the number of conspecifics (Population) negatively affected the mass of adults, but not of immatures. Finally, within the adult fraction, territorial birds showed higher body mass than nonterritorial individuals (Fig. 3).

\section{Discussion}

We found that oscillations in the availability of food (livestock and natural prey) and vulture population 

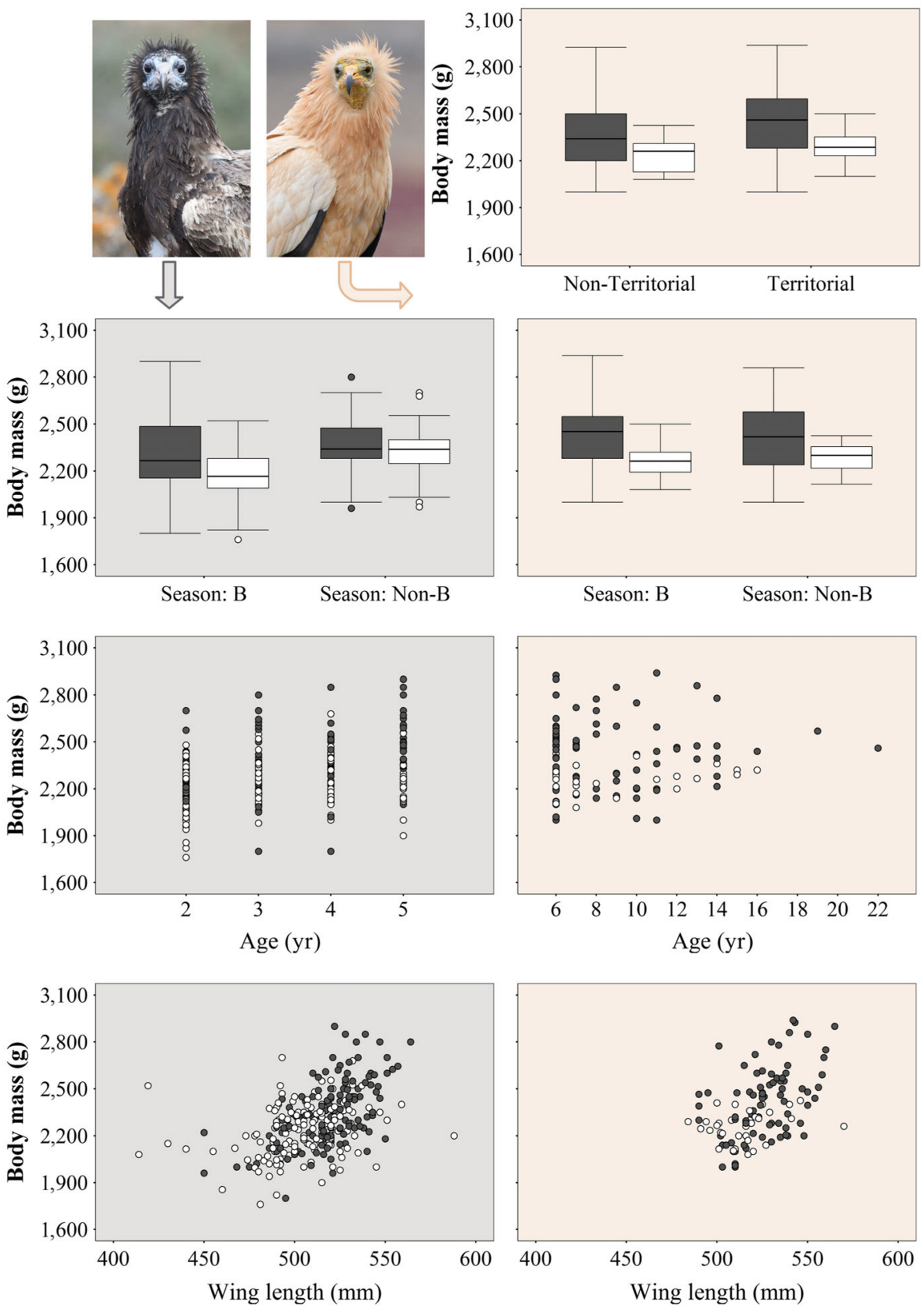

FIG. 1. Variation in body mass (g) for immature (2-5 yr old) and adult ( $\geq 6 \mathrm{yr}$ old), left and right columns, respectively. Variation is shown for male (white) and female (gray/black), from top to bottom, with respect to the territorial status (only adults), breeding season (B, breeding; Non-B, Non-breeding), age, and wing length. The line within boxes indicates the median, the edges of the boxes the first (Q1) and third (Q3) quartiles, and the whiskers extend 1.5 times the interquartile range. Photo credit: Manuel de la Riva.

density were key determinants explaining temporal changes in vultures' body mass. Importantly, the relative strength of individual, population and resource availability factors on body mass changed with life stage (i.e., immature vs. adults) and territorial status of adult birds, a pattern presumably shaped by differences in competitive abilities and/or age-dependent environmental knowledge and foraging skills (van Overveld et al. 2018). Even though this vulture population strongly depends on livestock carcasses as their main food source, a negative relationship was unexpectedly found between numbers of goat/sheep and average body mass of both adults and immatures.

\section{Environmental effects: NDVI and livestock}

Rather than a direct link between vulture body mass and landscape-scale primary productivity (and 

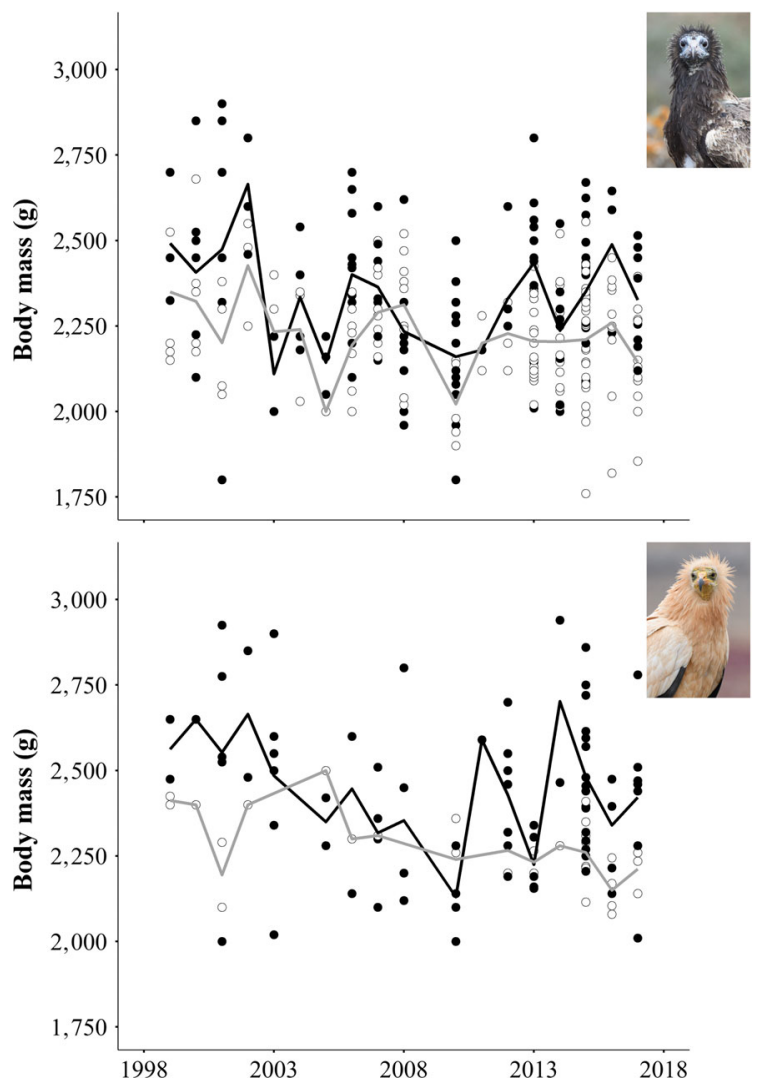

FIG. 2. Long-term changes in body mass of male (black points and line) and female (white points and gray line) Egyptian vultures captured across the study years (1998-2017). The upper panel shows data from immature birds ( $2-5 \mathrm{yr}$ old $)$, while the lower panel shows data from adults ( $\geq 6$ yr old). The lines connect annual means. Photo credit: Manuel de la Riva.

presumably a higher density of primary consumers; Schaub et al. 2005), a strong positive relationship was found between body mass and natural oscillations of local vegetation (i.e., high coefficient of variation of NDVI). More specifically, broad oscillations of NDVI (reflecting periods with both high and low primary productivity) may lead to greater mortality rates of wild herbivores such as rabbits and rodents, but also birds, for instance, due to unexpected drops in food available to these animals (short periods of rainfall followed by droughts; see Soudijn and de Roos 2017). Consequently, we could hypothesize that high variance in NDVI would lead to an overall increase in the availability of natural carcasses of wild herbivores that are a common food resource in the diet of island and mainland populations of Egyptian vultures, especially during the breeding season (Medina 1999, Margalida et al. 2012; see Data Availability). Within this scenario, the gain of mass by vultures during such unstable environmental conditions would fit within the socalled "fat storage strategy" (Wardle et al. 2012, Goławski et al. 2015), as has also been observed in bird populations from arid islands where food and water availability is intermittent (Grant 1965). In addition, fat storage can provide a reservoir of carotenoids (Negro et al. 2001, Metzger and Bairlein 2011), which are known to be essential immune stimulant and antioxidant micronutrients for this and other scavenger species (Negro et al. 2002, Blanco et al. 2013).

The negative relationship between livestock numbers and body mass is, however, surprising. We expected that fat reserves would accumulate under conditions of food bonanza, allowing vultures to build up an insurance against potential future food shortage or alternatively, to increase their investment during highly demanding periods such as reproduction (Weber et al. 1998). However, it is possible that in periods of food abundance (when future food prospects are generally good), vultures may trade-off fat storage against the benefits of being more agile (Lima 1986). On the other hand, while agility may confer important benefits while hunting (e.g., raptors) or escaping from predators (e.g., songbirds; Stankowich and Blumstein 2005, Macleod et al. 2008), this may not be true for a species such as the Egyptian vulture. They have very few natural predators (i.e., no records of predated Egyptian vultures exist on the Canary islands) and typically travel and search for carrion using soaring flight with little energy expenditure (Ruxton and Houston 2004). Furthermore, even though livestock densities showed strong fluctuations (between 70,000 and 150,000 animals), given an annual livestock mortality rate of $\sim 10 \%$, as in other areas with similar pastoral regimes (Margalida and Colomer 2012), this suggests that many carcasses have been available to vultures during the study period, even when livestock numbers reached minimum values. Hence, it is unclear why vultures would adaptively reduce their weight only in response to extreme high livestock densities, especially because the presence of many carcasses would allow vultures to reduce food searching efforts and flight activity.

As an alternative scenario, we therefore propose that an increase in cattle numbers and associated grazing pressure may have impacted vegetation structure and landscape-scale primary productivity (Liang and Gornish 2019), likely affecting other primary consumers on which vultures forage (Margalida et al. 2012). Indeed, in accordance with other studies (Sloat et al. 2018, Liang and Gornish 2019) we found that primary productivity was not only determined by precipitation (as would be expected), but also negatively affected by livestock numbers. Thus, our results would indicate that wild prey represents essential, but highly underestimated, resources, whose availability would affect vulture condition and fitness (Margalida et al. 2012). Wild prey may have also a qualitative importance linked to the fact that remains of small animals, including bones, provide essential micronutrients such as calcium (Reynolds and Perrins 2010) that are present to a much lesser extent in the soft tissues of ungulates (Houston 1978). It would deserve to 
TABLE 2. Estimates and standard errors resulting from the top ranked model of body mass for immature ( $\leq 5 \mathrm{yr}$ old $)$ and from model averaging of selected models for adult birds ( $\geq 6$ yr old).

\begin{tabular}{lcccc}
\hline \hline Variable & Estimate & SE & $7.5 \%$ & $92.5 \%$ \\
\hline Immatures & & & & 2283.9 \\
$\quad$ Intercept) & 2259.06 & 17.15 & 2234.3 & 51.07 \\
Age & 37.68 & 9.28 & 24.29 & 47.35 \\
CVNDVI6month & 34.14 & 9.14 & 20.88 & -16.17 \\
Livestock & -30.48 & 9.89 & -44.76 & 170.53 \\
Season & 143.05 & 19.04 & 115.59 & -46.1 \\
Sex & -76.21 & 20.8 & -106.49 & -55.62 \\
Sex $\times$ wing & -84.1 & 19.74 & -112.57 & 137.43 \\
Wing & 112.91 & 16.86 & 88.4 & 2457.85 \\
Adults & & & 2380.96 & 65.43 \\
(Intercept) & 2419.79 & 26.32 & 29.35 & -9.72 \\
CVNDVI6month & 47.04 & 12.44 & -63.17 & -8.68 \\
Livestock & -31.78 & 21.66 & -63.49 & -57.16 \\
Population & -25.26 & 23.06 & -170.71 & -19.64 \\
Sex & -115.3 & 39.03 & -127.12 & -13.78 \\
Sex $\times$ wing & -61.19 & 43.34 & -101.19 & 140.88 \\
Territory & -46.91 & 35.05 & 76.23 & 0.84 \\
Wing & 108.96 & 21.99 & & 0.69 \\
\hline
\end{tabular}

Notes: See Table 1 for a full description of each explanatory variable. Confidence intervals (7.5-92.5\%) of the estimates are also shown. RI shows the relative importance of each variable calculated as the sum of the Akaike weights over all of the models in which the term appears; this parameter is not shown for immatures because only one model was retained. Reference values of factorial explanatory variables (Sex, Territory, and Season) are shown for males, territorial adults and non-breeding season.

be investigated, however, why vultures do not compensate their weight loss (if due to the absence of natural prey) by an increase in the consumption of livestock.

\section{Individual and population effects}

As predicted by allometric relationships between size and mass in birds (Nudds 2007), we found that females (the largest) were also heavier compared to males. Interestingly, within each sex, a stronger relationship was found between body size and mass in females, suggesting that these traits are under stronger selection in the larger, but also more dominant sex. In females, individual performance may strongly depend on competitive skills. This allows them to feed more at predictable resources, while males in general avoid feeding in highly competitive resource environments (García-Heras et al. 2013, van Overveld et al. 2018). In line with this suggestion, taking into account effects of age on dominance rank, body size was positively correlated with dominance in females, but not in males (see Data Availability).

The effect of age on body mass of immature birds may reflect an improvement in their foraging skills over time, especially to locate carcasses of wild animals. Given the high annual rate of immature survival in our population (98\%; see Badia-Boher et al. 2019), we believe this pattern is due to acquired experience, rather than selective disappearance of lighter individuals (Forslund and Pärt 1995, Sanz-Aguilar et al. 2008). Within the adult fraction, territorial birds showed higher body mass than non-territorial ones (Fig. 3). This seems counterintuitive because the high energetic demands of reproduction usually lead to marked weight losses in birds (Ricklefs 1974), including vultures (Houston 1976). Again, the explanation for this pattern seems to be related to individual competitive abilities. Territorial birds are on average of higher dominance rank compared to nonterritorial ones (Penteriani et al. 2011, Tapia and Zuberogoitia 2018, van Overveld et al. 2018), which may provide a competitive advantage during food exploitation at predictable feeding sites and/or their territories may be located in food-rich areas. In addition, territorial adults may represent a subset of high-quality birds with well-developed foraging skills and environmental knowledge, allowing them to perform better in periods of high abundance of natural prey. While the body mass of adult vultures showed no response to seasonality, immatures were heavier during the non-breeding season. Seasonal variation in body mass among immatures could be linked to large-scale movements and energetically costly prospective activities that these birds perform during the population breeding season (van Overveld et al. 2018). At the end of this period, almost the entire non-breeding population concentrates in communal roosts and exploits more predictable resources and overall flight activity of vultures outside the breeding season is much lower (Donázar et al. 2002, van Overveld et al. 2018).

The finding of the effect of population growth over the study period on body mass is remarkable. Densitydependent processes have been invoked as regulators of body mass in other vertebrates (e.g., fishes; Dunham and Vinyard 2011) and there are numerous studies 


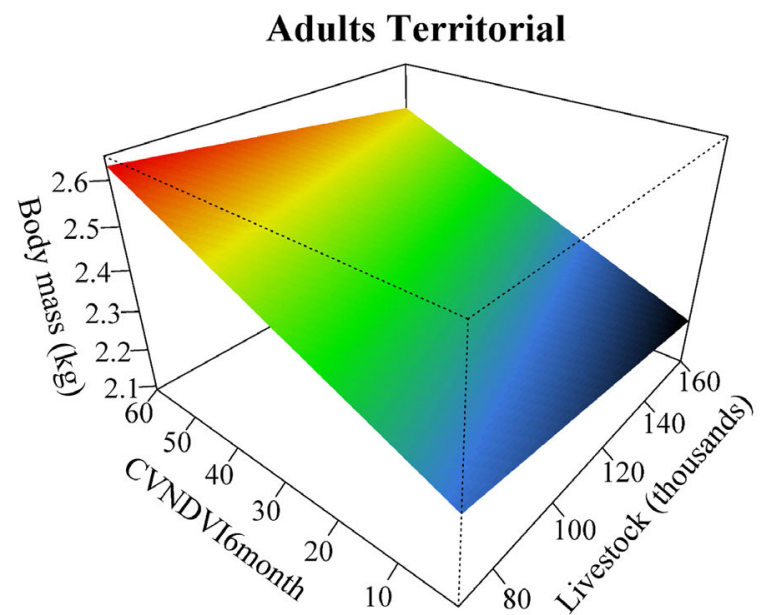

Immature Season: B

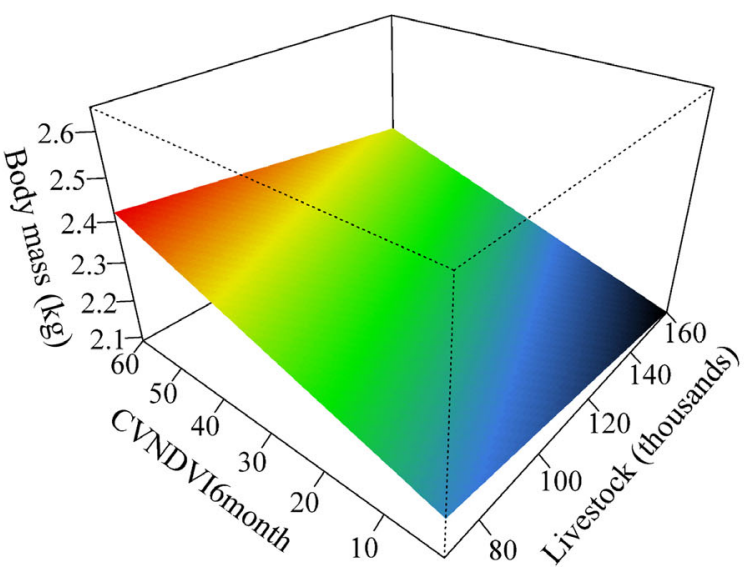

Adults Non-Territorial

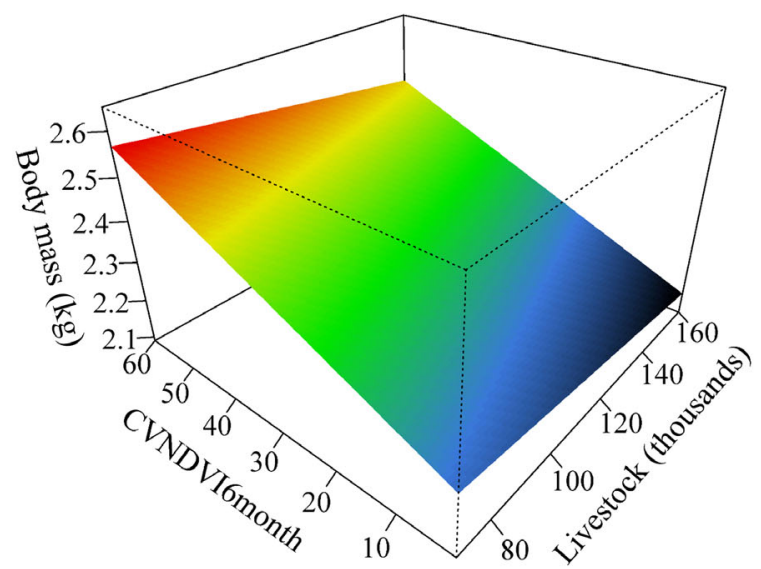

Immature Season: Non-B

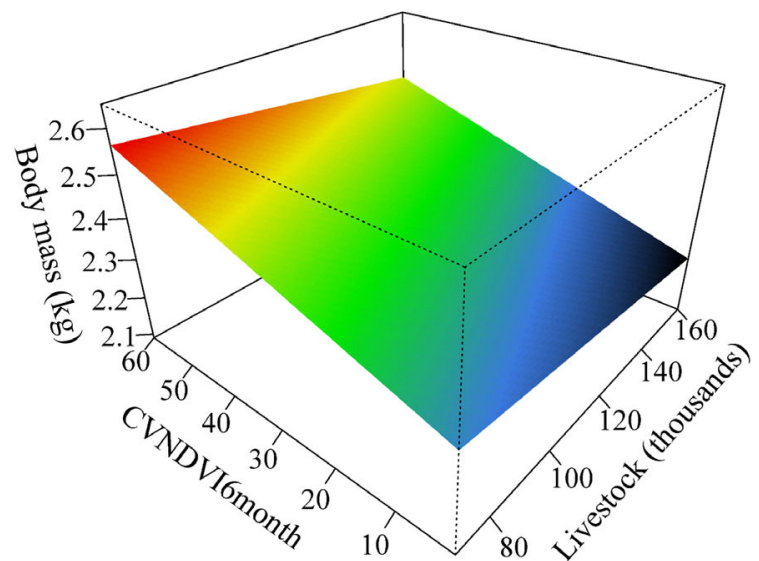

FIG. 3. Changes in body mass as predicted by the generalized linear mixed models (GLMMs) fitted for immature and adult data in relation to variables evaluating long-term changes in primary productivity (Table 2). CVNDVI6: coefficient of variation of monthly values (daily averages) during the six months prior to the capture. Livestock: numbers of head (goats and sheep) in Fuerteventura Island. Breeding season: B, breeding; Non-B, non-breeding. Models were fitted for values corresponding to females. We applied the average of the range values for the rest of the variables fitted into the model.

indicating that in very dense populations, the individual condition worsens (Vincent et al. 1995, Saidapur and Girish 2001, MacDonald et al. 2002, Rogers et al. 2009). Although increasing competition for food resources is known to shape population parameters in growing populations of other vultures (Carrete et al. 2006, Fernández-Bellon et al. 2016), the overall importance of these processes in bird populations is largely unknown. We found that population size negatively affected vultures' body mass, but only within the adult fraction of the population. It could be hypothesized that this effect is mainly driven by competition for natural food resources. The absence of a density-dependent effect in immatures is intriguing and suggests age-specific differences in resource competition, as well as energetic costs associated with sexual and social competition for mates/territories and resource defense. Moreover, immatures rely more on predictable resources such as feeding stations and large farms despite their overall low social position (van Overveld et al. 2018). It would be interesting to address in future studies whether wild prey could become a key factor limiting population growth, despite the presence of an overabundance of goats.

\section{Synthesis and perspectives}

The influence of human-mediated transformation on grazing biomes through livestock pressure jointly interacts with climatic conditions to determine the landscapescale primary productivity. Currently, populations of three endemic scavengers (Egyptian vultures, Ravens, and Common Buzzard) in the study area largely depend on goat carcasses, as occurs in other insular systems (Gangoso et al. 2006, 2013). Thus, increasing livestock numbers would be expected to favor vulture body condition. Our study, however, shows that small wild prey 
may represent an underestimated component in the diet of Egyptian vultures (Margalida et al. 2012). As such, high livestock numbers and associated overgrazing effects can even have a negative influence on vultures' body condition, with potential important consequences on individual fitness (Stearns 1992, Williams 2012). These conflicting effects of livestock production must be taken into account in conservation programs for obligate and facultative scavenger species whose diet also includes wild primary consumers, especially in a context where worldwide grazing pressure is growing exponentially. Therefore, assuming that higher livestock densities result in direct positive effects for endangered vulture populations can be a manifest error. An integral management strategy will be required to allow the maintenance of biodiversity in grazed areas, especially on islands sensitive to drought events and regions where the effects of environmental modifications, including climate change, are expected to be strong (Arévalo et al. 2012).

\section{Acknowledgments}

Population monitoring was done by J. Roldan, W. Moreno, J. Ramírez, S. Sierra, C. Díez, M. Mallo, R. Agudo, A. Trujillano, and C. J. Palacios. O. Ceballos, F. Hiraldo, A. Sanz-Aguilar, A. Cortés-Avizanda, V. Saravia, K. Heissenberger, M.-S. GarcíaHeras, M. A. Cabrera and F. Rodríguez also helped with the fieldwork. The Consejería de Agricultura, Ganadería, Pesca y Aguas del Gobierno de Canarias provided data on livestock numbers. The study was funded by the Cabildo Insular de Fuerteventura, Viceconsejería de Medio Ambiente del Gobierno de Canarias, the Research Projects REN 2000- 1556 GLO, CGL2004-00270, CGL2012-40013-C02-01, CGL201566966-C2-1-2-R and RTI2018-099609-B-C21 (Spanish Ministry of Economy and Competitiveness and EU/FEDER), and the Severo Ochoa Excellence Award from the Ministerio de Economía y Competitividad (SEV-2012-0262). M.García-Alfonso was supported by a contract from "Programa de FPU del Ministerio de Educación, Cultura y Deporte" (FPU13/05429). T. V. Overveld received funding from the European Union's Horizon 2020 research and innovation program under the Marie Sklodowska-Curie grant agreement "SocForVul 659008." During the writing of this manuscript, a Marie Sklodowska-Curie Fellowship from the European Commission (grant number 747729, EcoEvoClim) supported L. Gangoso and J. M. Barbosa was supported by the Juan de la Cierva fellowship.

\section{LITERATURE CITED}

Arévalo, J. R., S. Fernández-Lugo, L. de Nascimento, L. A. Bermejo, and A. Naranjo. 2012. Grazing management and impact in the Canary islands: Rethinking sustainable use. Pages 41-57 in J. Arevalo, editor. Grazing ecology: vegetation and soil impact. Nova Science Publishers, Hauppauge, New York, USA.

Arnold, T. W. 2010. Uninformative parameters and model selection using Akaike's information criterion. Journal of Wildlife Management 74:1175-1178.

Ashton, K. G. 2002. Patterns of within-species body size variation of birds: strong evidence for Bergmann's rule. Global Ecology and Biogeography 11:505-523.

Badia-Boher, J. A., A. Sanz-Aguilar, M. de la Riva, L. Gangoso, T. van Overveld, M. García-Alfonso, O. P. Luzardo, A. Suarez-Pérez, and J. A. Donázar. 2019. Evaluating European
LIFE conservation projects: Improvements in survival of an endangered vulture. Journal of Applied Ecology 56:1210 1219.

Barton, K.2017. MuMIn: Multi-model inference. R package version 1.43.15. https://CRAN.R-project.org/package= MuMIn

Bates, D., M. Mächler, B. Bolker, and S. Walker. 2014. Fitting linear mixed-effects models using lme4. Journal of Statistical Software 67:1-48.

Beschta, R. L., D. L. Donahue, D. A. Dellasala, J. J. Rhodes, J. R. Karr, M. H. O'Brien, T. L. Fleischner, and C. Deacon Williams. 2013. Adapting to climate change on western public lands: addressing the ecological effects of domestic, wild, and feral ungulates. Environmental Management 51:474-491.

Blanco, G., D. Hornero-Méndez, S. A. Lambertucci, L. M. Bautista, G. Wiemeyer, J. A. Sanchez-Zapata, J. GarridoFernández, F. Hiraldo, and J. A. Donázar. 2013. Need and seek for dietary micronutrients: endogenous regulation, external signalling and food sources of carotenoids in new world vultures. PLoS ONE 8:e65562.

Burnham, K., and D. Anderson 2002. Model selection and multimodel inference: a practical information-theoretic approach. Second edition. Springer, New York, New York, USA.

Buschke, F., M. Kemp, M. Seaman, and S. Louw. 2011. Intraannual variation of arthropod-plant interactions and arthropod trophic structure in an endangered grassland in the Free State province, South Africa. African Journal of Range and Forage Science 28:57-63.

Carrete, M., J. A. Donázar, and A. Margalida. 2006. Densitydependent productivity depression in Pyrenean Bearded Vultures: Implications for conservation. Ecological Applications 16:1674-1682.

Chapuis, J. L., P. Boussès, and G. Barnaud. 1994. Alien mammals, impact and management in the French subantarctic islands. Biological Conservation 67:97-104.

Chastel, O., H. Weimerskirch, and P. Jouventin. 1995. Influence of body condition on reproductive decision and reproductive success in the blue petrel. Auk 112:964-972.

Clements, C. F., and A. Ozgul. 2016. Including trait-based early warning signals helps predict population collapse. Nature Communications 7:1-8.

Coblentz, B. E. 1978. The effects of feral goats (Capra hircus) on island ecosystems. Biological Conservation 13:279-286.

Coulson, T., D. R. MacNulty, D. R. Stahler, B. VonHoldt, R. K. Wayne, and D. W. Smith. 2011. Modeling effects of environmental change on wolf population dynamics, trait evolution, and life history. Science 334:1275-1278.

Couturier, S., S. D. Côté, R. D. Otto, R. B. Weladji, and J. Huot. 2009. Variation in calf body mass in migratory Caribou: the role of habitat, climate, and movements. Journal of Mammalogy 90:442-452.

Darkoh, M. B. K. 2003. Regional perspectives on agriculture and biodiversity in the drylands of Africa. Journal of Arid Environments 54:261-279.

De La Maza, M., M. Lima, P. L. Meserve, J. R. Gutiérrez, and F. M. Jaksic. 2009. Primary production dynamics and climate variability: ecological consequences in semiarid Chile. Global Change Biology 15:1116-1126.

Deichmann, J. L., C. A. Toft, P. M. Deichmann, A. P. Lima, and G. B. Williamson. 2012. Neotropical primary productivity affects biomass of the leaf-litter herpetofaunal assemblage. Journal of Tropical Ecology 28:427-435.

Donázar, J. A., C. J. Palacios, L. Gangoso, O. Ceballos, M. J. González, and F. Hiraldo. 2002. Conservation status and limiting factors in the endangered population of Egyptian vulture (Neophron percnopterus) in the Canary Islands. Biological Conservation 107:89-97. 
Donázar, J. A., L. Gangoso, M. G. Forero, and J. Juste. 2005. Presence, richness and extinction of birds of prey in the Mediterranean and Macaronesian islands. Journal of Biogeography 32:1701-1713.

Donázar, J. A., A. Margalida, M. Carrete, and J. A. SánchezZapata. 2009. Too sanitary for vultures. Science 326:664.

Duncan, C., A. L. M. Chauvenet, M. E. Brown, and N. Pettorelli. 2015. Energy availability, spatio-temporal variability and implications for animal ecology. Diversity and Distributions 21:290-301.

Dunham, J. B., and G. L. Vinyard. 2011. Relationships between body mass, population density, and the self-thinning rule in stream-living salmonids. Canadian Journal of Fisheries and Aquatic Sciences 54:1025-1030.

Ellis, E. C. 2011. Anthropogenic transformations of the terrestrial biosphere. Proceedings of the Royal Society A: Mathematical, Physical and Engineering Science 369:1010-1035.

Fernández-Bellon, D., A. Cortés-Avizanda, R. Arenas, and J. A. Donázar. 2016. Density-dependent productivity in a colonial vulture at two spatial scales. Ecology 97:406-416.

Fillios, M., C. Gordon, F. Koch, and M. Letnic. 2010. The effect of a top predator on kangaroo abundance in arid Australia and its implications for archaeological faunal assemblages. Journal of Archaeological Science 37:986-993.

Forslund, P., and T. Pärt. 1995. Age and reproduction in birds hypotheses and tests. Trends in Ecology \& Evolution 10:374 378.

Forsman, D. 2007. The raptors of Europe and the Middle East. A handbook to field identification. Christopher Helm, Dundee, UK.

Gangoso, L., J. A. Donázar, S. Scholz, C. J. Palacios, and F. Hiraldo. 2006. Contradiction in conservation of island ecosystems: Plants, introduced herbivores and avian scavengers in the Canary Islands. Biodiversity and Conservation 15:2231-2248.

Gangoso, L., R. Agudo, J. D. Anadón, M. De la Riva, A. S. Suleyman, R. Porter, and J. A. Donázar. 2013. Reinventing mutualism between humans and wild fauna: Insights from vultures as ecosystem services providers. Conservation Letters 6:172-179.

García-Heras, M.-S., A. Cortés-Avizanda, and J.-A. Donázar. 2013. Who are we feeding? Asymmetric individual use of surplus food resources in an insular population of the endangered Egyptian vulture Neophron percnopterus. PLOS ONE 8.

Goławski, A., M. Polakowski, P. Filimowski, K. Stepniewska, K. Stępniewski, G. Kiljan, and D. Kilon. 2015. Factors influencing the fat load variation in three wintering bird species under stable food access conditions. Journal of Ethology 33:205-211.

Grahman, M. H. 2003. Confronting multicollinearity in ecological multiple regression. Ecology 84:2809-2815.

Grant, P. R. 1965. The fat condition of some island birds. Ibis 107:350-356.

Heuck, C., C. Herrmann, D. G. Schabo, R. Brandl, and J. Albrecht. 2017. Density-dependent effects on reproductive performance in a recovering population of White-tailed Eagles Haliaeetus albicilla. Ibis 159:297-310.

Houston, D. C. 1976. Breeding of the white-backed and Rüppell's griffon vultures, Gyps africanus and G. rueppellii. Ibis 118:14-40.

Houston, D. C. 1978. The effect of food quality on breeding strategy in Griffon vultures (Gyps spp.). Journal of Zoology 186:175-184.

Hunter, M. D. 1992. Interactions within herbivore communities mediated by the host plant: the Keystone herbivore concept. Pages 287-325 in P. W. Hunter, M. D. Ohgushi, and T. Price, editors. Effects of resource distribution on animal-plant interactions. Academic Press, San Diego, California, USA.

Liang, M., and E. S. Gornish. 2019. Rainfall regulation of grazed grasslands. Proceedings of the National Academy of Sciences USA 116:201915399.

Lima, S. L. 1986. Predation risk and unpredictable feeding conditions: determinants of body mass in birds. Ecology 67:377385

MacDonald, D. W., C. Newman, P. D. Stewart, X. DomingoRoura, and P. J. Johnson. 2002. Density-dependent regulation of body mass and condition in badgers (Meles meles) from Wytham woods. Ecology 83:2056-2061.

Macleod, R., J. Clark, and W. Cresswell. 2008. The starvationpredation risk trade-off, body mass and population status in the Common Starling Sturnus vulgaris. Ibis 150:199-208.

Margalida, A., and M. À. Colomer. 2012. Modelling the effects of sanitary policies on European vulture conservation. Scientific Reports 2:753.

Margalida, A., J. R. Benítez, J. A. Sánchez-Zapata, E. Ávila, R. Arenas, and J. A. Donázar. 2012. Long-term relationship between diet breadth and breeding success in a declining population of Egyptian Vultures Neophron percnopterus. Ibis 154:184-188.

Margalida, A., M. À. Colomer, and D. Oro. 2014. Man-induced activities modify demographic parameters in a long-lived species: Effects of poisoning and health policies. Ecological Applications 24:436-444.

Mazerolle, M.2019. Model Selection and Multimodel Inference Based on (Q)AIC(c) Version 2.2-2 Date. https://cran.r-projec t.org/package $=$ AICcmodavg

Medina, F. M. 1999. Alimentación del alimoche, Neophron percnopterus (L.), en Fuerteventura, Islas Canarias (Aves, Accipitridae). Vieraea 27:77-86.

Metzger, B. J., and F. Bairlein. 2011. Fat stores in a migratory bird: A reservoir of carotenoid pigments for times of need? Journal of Comparative Physiology B: Biochemical, Systemic, and Environmental Physiology 181:269-275.

Milenkaya, O., N. Weinstein, S. Legge, and J. R. Walters. 2013. Variation in body condition indices of crimson finches by sex, breeding stage, age, time of day, and year. Conservation Physiology $1: 1-14$.

Negro, J. J., J. Figuerola, J. Garrido, and A. J. Green. 2001. Fat stores in birds: An overlooked sink for carotenoid pigments? Functional Ecology 15:297-303.

Negro, J. J., J. M. Grande, J. L. Tella, J. Garrido, D. Hornero, J. A. Donázar, J. A. Sanchez-Zapata, J. R. BenÍtez, and M. Barcell. 2002. An unusual source of essential carotenoids. Nature 416:807-808

Nudds, R. L. 2007. Wing-bone length allometry in birds. Journal of Avian Biology 38:515-519.

O’Neal, M. 2015. Vultures: their evolution, ecology and conservation. Apple Academic Press, Palm Bay, Florida, USA.

Pandey, C. B., and J. S. Singh. 1992. Rainfall and grazing effects on net primary productivity in a tropical savanna, India. Ecology 73:2007-2021.

Penteriani, V., M. Ferrer, and M. M. Delgado. 2011. Floater strategies and dynamics in birds, and their importance in conservation biology: Towards an understanding of nonbreeders in avian populations. Animal Conservation 14:233-241.

Pettorelli, N., R. B. Weladji, Ø. Holand, A. Mysterud, H. Breie, and N. C. Stenseth. 2005. The relative role of winter and spring conditions: Linking climate and landscape-scale plant phenology to alpine reindeer body mass. Biology Letters $1: 24-26$

Pettorelli, N., F. Pelletier, A. von Hardenberg, M. Festa-Bianchet, and S. D. Côté. 2007. Early onset of vegetation growth 
vs. rapid green-up: impacts on juvenile mountain ungulates. Ecology 88:381-390.

Pierce, B. M., V. C. Bleich, K. L. Monteith, and R. T. Bowyer. 2012. Top-down versus bottom-up forcing: evidence from mountain lions and mule deer. Journal of Mammalogy 93:977-988.

R Core Team, D. C. 2017. A language and environment for statistical computing. R Foundation for Statistical Computing, Vienna, Austria. www.R-project.org

Reynolds, S. J., and C. M. Perrins 2010. Dietary calcium availability and reproduction in birds. Pages 31-74 in C. Thompson, editor. Current ornithology. Volume 17. Springer US, New York, New York, USA.

Ricklefs, R. 1974. Energetics of reproduction in birds. Pages 152-159 in R. A. Paynter, editor. Avian energetics. Nuttall Ornithology Club, Cambridge, UK.

Rioux Paquette, S., F. Pelletier, D. Garant, and M. Bélisle. 2014. Severe recent decrease of adult body mass in a declining insectivorous bird population. Proceedings of the Royal Society B: Biological Sciences 281:20140649.

Rogers, L. M., C. L. Cheeseman, and S. Langton. 2009. Body weight as an indication of density-dependent population regulation in badgers (Meles meles) at Woodchester Park, Gloucestershire. Journal of Zoology 242:597-604.

Rosenblatt, A. E. 2018. Shifts in plant nutrient content in combined warming and drought scenarios may alter reproductive fitness across trophic levels. Oikos 127:1853-1862.

Ruxton, G. D., and D. C. Houston. 2004. Obligate vertebrate scavengers must be large soaring fliers. Journal of Theoretical Biology 228:431-436.

Saidapur, S. K., and S. Girish. 2001. Growth and metamorphosis of Bufo melanostictus Tadpoles: effects of kinship and density. Journal of Herpetology 35:249-254.

Simard, M. A., T. Coulson, A. Gingras, and S. D. Côté. 2010. Influence of density and climate on population dynamics of a large herbivore under harsh environmental conditions, Journal of Wildlife Management. 74:1671-1685. https://doi.org/ $10.2193 / 2009-258$

Sanz-Aguilar, A., G. Tavecchia, R. Pradel, E. Minguez, and D. Oro. 2008. The cost of reproduction and experience-dependent vital rates in a small petrel. Ecology 89:3195-3203.

Schaub, M., W. Kania, and U. Köppen. 2005. Variation of primary production during winter induces synchrony in survival rates in migratory white storks Ciconia ciconia. Journal of Animal Ecology 74:656-666.

Sloat, L. L., J. S. Gerber, L. H. Samberg, W. K. Smith, M. Herrero, L. G. Ferreira, C. M. Godde, and P. C. West. 2018. Increasing importance of precipitation variability on global livestock grazing lands. Nature Climate Change 8:214-218.
Soudijn, F. H., and A. M. de Roos. 2017. Predator persistence through variability of resource productivity in tritrophic systems. American Naturalist 190:844-853.

Stankowich, T., and D. T. Blumstein. 2005. Fear in animals: A meta-analysis and review of risk assessment. Proceedings of the Royal Society B 272:2627-2634.

Stearns, S. C. 1992. The evolution of life-histories. Oxford University Press, Oxford, UK.

Sugiura, N. 1978. Further analysis of the data by Akaike's information criterion and the finite corrections. Communications in Statistics-Theory and Methods 7:13-26.

Tapia, L., and I. Zuberogoitia. 2018. Breeding and nesting biology in raptors. Pages 63-94 in J. J. Sarasola, H. Grande, and J. M. Negro, editors. Birds of prey. Biology and conservation in the XXI century. Springer, Berlin Heidelberg.

Van Buskirk, J., R. S. Mulvihill, and R. C. Leberman. 2010. Declining body sizes in North American birds associated with climate change. Oikos 119:1047-1055.

van Overveld, T., M. García-Alfonso, N. J. Dingemanse, W. Bouten, L. Gangoso, M. de la Riva, D. Serrano, and J. A. Donázar. 2018. Food predictability and social status drive individual resource specializations in a territorial vulture. Scientific Reports 8.

Vermote, E., C. Justice, I. Csiszar, J. Eidenshink, R. B. Myneni, F. Baret, E. Masuoka, R. E. Wolfe, M. Claverie, and NOAA CDR Program. 2014. NOAA Climate Data Record (CDR) of Normalized Difference Vegetation Index (NDVI), Version 4. NOAA National Centers for Environmental Information. https://doi.org/10.7289/V5PZ56R6

Vincent, J. P., E. Bideau, A. J. M. Hewison, and J. M. Angibault. 1995. The influence of increasing density on body weight, kid production, home range and winter grouping in roe deer (Capreolus capreolus). Journal of Zoology 236:371382 .

Wardle, D. A., M. Jonsson, M. Kalela-Brundin, A. Lagerström, R. D. Bardgett, G. W. Yeates, and M. C. Nilsson. 2012. Drivers of inter-year variability of plant production and decomposers across contrasting island ecosystems. Ecology 93:521531.

Weber, T. P., B. J. Ens, and A. I. Houston. 1998. Optimal avian migration: A dynamic model of fuel stores and site use. Evolutionary Ecology 12:377-401.

Williams, T. D. 2012. Physiological adaptations for breeding in birds. Princeton University Press, Princeton, New Jersey, USA.

Zeder, M. A. 2008. Domestication and early agriculture in the Mediterranean Basin: Origins, diffusion, and impact. Proceedings of the National Academy of Sciences USA 105:11597-11604.

\section{SUPPORTING INFORMATION}

Additional supporting information may be found online at: http://onlinelibrary.wiley.com/doi/10.1002/eap.2125/full

\section{Data Availability Statement}

Data are available from the Dryad Digital Repository: https://doi.org/10.5061/dryad.02v6wwq0d 